\section{Factors related to poor self-perceived oral health among community-dwelling elderly individuals in São Paulo, Brazil}

\author{
Fatores associados à autopercepção de saúde \\ bucal ruim entre idosos não institucionalizados \\ do Município de São Paulo, Brasil
}

\author{
${ }^{1}$ Faculdade de Saúde \\ Pública, Universidade de São \\ Paulo, São Paulo, Brasil. \\ 2 Faculdade de Medicina de \\ Ribeirão Preto, Universidade \\ de São Paulo, Ribeirão Preto, \\ Brasil. \\ ${ }^{3}$ Escola de Enfermagem, \\ Universidade de São Paulo, \\ São Paulo, Brasil. \\ Correspondence \\ F. B. Andrade \\ Faculdade de Saúde Pública, \\ Universidade de São Paulo. \\ Av. Dr. Arnaldo 715, São \\ Paulo, SP 01246-904, Brasil. \\ fabiolabof@yahoo.com.br
}

\begin{abstract}
The present study investigated the prevalence of poor self-perceived oral health and its association with oral health, general health and socioeconomic factors among elderly individuals from São Paulo, Brazil. The sample consisted of 871 elderly individuals enrolled in the Health, Wellbeing and Aging cohort study. Self-perceived oral health was measured by the question: "How would you rate your oral health?”. Most subjects self-rated their oral health as good. Among dentate individuals, poor oral health was related to depression, poor self-rated health, dental treatment, dental checkups and the psychosocial subscale scores of the Geriatric Oral Health Assessment Index. Edentulous individuals were more likely to report poor oral health, whereas those with higher psychosocial scores were less likely to report poor self-rated oral health. Poor self-rated oral health is associated with general health factors and the psychosocial impact of oral health on quality of life, regardless of socioeconomic and clinical health measures.
\end{abstract}

Oral Health; Quality of Life; Aged
Fabiola Bof de Andrade 1

Maria Lúcia Lebrão ${ }^{1}$

Jair Lício Ferreira Santos 2

Yeda Aparecida de Oliveira Duarte ${ }^{3}$

Doralice Severo da Cruz Teixeira 1

\section{Introduction}

Population aging is a universal phenomenon that needs to be tackled as a major issue due to its impact on public health expenditure and quality of life. In relation to oral health, although a number of studies have demonstrated a worldwide decrease in tooth loss among all age groups 1,2, the latest epidemiological survey in Brazil found that the mean number of decayed, missing and filled teeth among individuals aged 65 to 74 years was 27.53. The missing teeth component accounted for $91.9 \%$ of the index and $97.7 \%$ of these elderly individuals needed prostheses 3 . However, the same study reports that $44.5 \%$ of the individuals in this age group were satisfied with their oral health ${ }^{3}$. This apparent contradiction has been reported in other studies 4,5.6,7. According to the literature, individuals with unsatisfactory objective oral health conditions may perceive their oral health as positive because the general focus of clinical measures is morbidity 8 whereas subjective measures of assessing health ${ }^{9}$ represent the perceptions and judgments of individuals regarding their own health based on both individual and social beliefs and concepts 9 .

Clinical measures are related to disease indicators (e.g., tooth loss, number of decayed teeth, need for prostheses, etc.) and are thought to be difficult to interpret in the planning and evaluation of public health programs, as it is impossible to determine who among a large number 
of affected subjects will seek care 10 . Although self-perceived oral health is related to clinical measures 6,11,12, discrepant results are reported and the evidence suggests that individuals place more importance on factors related to the psychosocial and functional impact of oral health on quality of life when self-assessing their own oral health 13,14 . In the same vein, some authors 14 have suggested that the differences between self-perceived oral health and clinical indicators may be the main reason for individuals not seeking oral health care when it is available. There is an increasing interest in studying self-perceived oral health as a way of complementing information obtained from clinical indicators 15,16 and allowing for better planning of health services $12,17,18$. Despite the increase in evidence regarding this issue, there remains a lack of comprehensive data on determinants of self-perceived oral health. Moreover, data available from nationwide epidemiological surveys in Brazil is restricted to individuals up to the age of 74 which does not permit the investigation of outcomes among older individuals that represent an increasing proportion of the population. At the time of writing this article, to the best of our knowledge, no other large representative study with updated information had been carried out in the country regarding self-perceived oral health among the elderly. Thus, considering the importance of producing confirmatory findings and evaluating the self-perception of oral health across time, as has been done through repeated national epidemiological surveys, the aim of the present study was to determine the prevalence of poor self-perceived oral health and its association with oral health indicators, general health measures and socioeconomic factors among a representative sample of elderly Brazilians.

\section{Material and methods}

A cross-sectional study was carried out using data from the second wave of the Health, Wellbeing and Aging Cohort Study (Saúde, Bem-estar e Envelhecimento-SABE). The first wave was a multicenter project coordinated by the Pan-American Health Organization (PAHO) conducted in seven countries in Latin America and the Caribbean (Argentina, Barbados, Brazil, Chile, Cuba, Mexico and Uruguay). In Brazil, this study was conducted in the city of São Paulo in 2000 and 2001 and involved 2,143 elderly individuals aged 60 years and over, selected using multiple-stage sampling. The initial sample of 2,143 individuals was made up of two segments. The first was the result of a selection in lots and corresponded to a probabilistic sample comprising 1,568 interviewees. The second was made up of 575 residents of districts of São Paulo who undertook the same interview and represented an increase to compensate for the death of individuals over 75 years of age to complete the desired number of interviewees in this age group. Cluster sampling was used to select residences in lots, carried out in two stages using the partition criterion proportional to size. A permanent registry of 72 census sectors at the Epidemiology Department of the School of Public Health of Sao Paulo University (Departamento de Epidemiologia, Faculdade de Saúde Pública, Universidade de São Paulo FSP/USP) was considered the first-stage sample. This sample was taken from the records of the National Household Sample Survey (PNAD 1995), made up of 263 census sectors selected in lots using the probability criterion proportional to the number of residences. The minimal number of residences in the second stage was estimated at 90. The complementation of the sample with individuals aged 75 years or over was performed with residences in close proximity to the selected sector or at least within the boundaries of the districts to which the selected sectors belonged. Each questionnaire was weighted based on the census sector to which it belonged (weight $=1 /$ f). For the questionnaires of individuals from residences that were selected but not randomly determined in lots (aged 75 years or over), weighting was determined in relation to the elderly population in this age group in the city of São Paulo in 1998 and the number of individuals in this age group in the final sample of the study 19,20. A detailed description of the methodology employed can be found in Lebrão \& Duarte 19 .

In 2006, the survey was continued in São Paulo and was transformed into a cohort study. In this follow-up study, 1,115 of the individuals who had participated in the baseline study were located and agreed to undergo a new set of interviews using the same procedures as well as an oral health clinical examination performed by trained, calibrated examiners (mean kappa index for the inter-examiner agreement: 0.90 and 0.83 for dental and periodontal examination, respectively). Self-perceived oral health and clinical oral health measures were only introduced into the second wave of the study, thus it was not possible to compare differences in relation to these variables between remaining individuals in the follow-up and losses.

All data was collected at the participants' homes by trained examiners and included an interviewer-administered structured questionnaire with questions on socioeconomic and general health factors as well as the self-perceived 
impact of oral health on quality of life using the physical function, psychosocial function and pain/discomfort subscales of the General Oral Health Assessment Index (GOHAI) 13. All questionnaires went through a data check before data entry and any inconsistency was clarified with the participant by telephone or a new home visit. The databank was also reviewed for any inconsistencies.

In this study the dependent variable was self-perceived oral health measured by the question "How would you rate your oral health?". The answers were based on a five-point Likert scale and dichotomized into "poor" (fair/poor/ very poor) and "good" (good/very good) 5,21. The following independent variables were used: (1) socio-demographic factors: age (continuous), gender (male and female), self-perception of sufficient income for basic expenses (yes and no) and schooling (0-3, 4-7 and 8+ years); (2) general health: depression 22,23 (yes and no), number of self-reported chronic diseases (0-1 and 2+ diseases: diabetes, hypertension, heart disease, chronic obstructive pulmonary disease and arthritis), self-perceived general health (good and poor) and smoking status (yes and no); (3) oral health measures: number of teeth $(0,1-10,11$ $20,21+$ teeth), use of dental prosthesis (yes and no), need for dental prosthesis (yes and no), presence of decayed teeth (yes and no), clinical attachment loss $\geq 4 \mathrm{~mm}$ (yes and no), periodontal pocket $\geq 4 \mathrm{~mm}$ (yes and no), time since last dental visit ( $\leq 2$ and $3+$ years) and reason for last dental visit (urgent care, treatment and checkup) and; (4) self-perceived impact of oral health on quality of life using the GOHAI physical function, psychosocial function and pain/discomfort subscales (continuous variables).

Statistical analysis included descriptive and inferential analyses, with a $5 \%$ significance level and $95 \%$ confidence interval $(95 \% \mathrm{CI})$. Associations between categorical variables were tested using the Rao-Scott test, which takes into account design weighting stemming from complex sampling procedures 24 . Differences between means were evaluated using the adjusted Wald test. All independent predictors with a p-value < 0.20 from bivariate analysis were entered into a multiple logistic regression model using the forward stepwise method in the following order: socioeconomic, general health, oral health measures and GOHAI. The model was adjusted for age (continuous variable), depression and selfperception of sufficient income (both answers dichotomized as yes or no). Participants diagnosed with cognitive impairment were excluded from the analysis 25 . Logistic regression was used to estimate the probabilities of poor self-rated oral health $(\mathrm{y}=1)$. The variance inflation factor (VIF) was used to assess collinearity between the independent variables. A VIF under 10 is considered acceptable 26 . Collinearity was observed in relation to the GOHAI subscales in all three of the final models. However, as can be seen with the multivariate logistic regression, the inclusion of these variables in the final adjusted model did not lead to noteworthy changes in the significant predictors and in some cases an adjustment of the variables was observed. According to the literature, collinearity makes it more difficult to achieve significance of the collinear parameters. However, when such estimates are statistically significant they are as reliable as any other variables in a model 27 and may be left in the model regardless of the results of collinearity test 26 and a model with these variables was therefore also presented. However, since the independent predictors were included in blocks, all of which are presented, it is also possible to view the analysis without including these factors. Moreover, this decision allowed for comparisons with other studies that used similar approaches.

The Stata 11.0 software (Stata Corp., College Station, USA) was used for data analysis and design effect correction for data from a complex sample was performed using the "survey" command. New weightings were calculated to maintain the representativity of the 2006 wave of the study. The available total sample was sufficient to detect a statistically significant odds ratio of 1.33 or greater associated with poor selfperceived oral health with a significance level of 0.05 and power of 0.80 for an exposure rate ranging from 0.20 to 0.80 . Regarding the dentate and edentate sample, the significance level was 0.05 with a power of 0.80 for an exposure rate ranging from 0.20 to 0.80 with detected odds ratios as low as 1.51 and 1.47 , respectively.

This study received approval from the Human Ethics Research Committee of the FSP/USP and written informed consent was obtained from the subjects before carrying out the interviews.

\section{Results}

Losses occurred between the baseline and follow-up due to the following reasons: deaths (22.93\%); subject unlocatable (7.8\%); moved to another city (2.5\%); institutionalization $(0.35 \%)$ and refusals $(9.62 \%)$. Compared with the group lost to follow-up, the remaining individuals from the cohort, at baseline, were significantly more likely to be women, young, non smokers, live with someone, have up to one disease and higher mean physical GOHAI scores. 
No differences were found between the group lost to follow-up and remaining individuals from the cohort in relation to level of education, selfperception of sufficient income, self-perceived general health status, depression, psychosocial function and the pain/discomfort subscales of the GOHAI. In $2006,11.81 \%$ of the 1,115 individuals remaining in the cohort were excluded due to cognitive decline and $2.61 \%$ due to lack of information regarding cognitive decline, leaving a total of 871 individuals (representing 606,071 elderly individuals) with completed information regarding the dependent variable. However, missing values in different variables meant that $5.29 \%, 7.64 \%$ and $5.06 \%$ of individuals were excluded from the dentate, edentate and multivariate models respectively.

Regarding the dependent variable, most of the elderly individuals self-rated their oral health as good $(74.36 \%)$. The same pattern was observed in relation to dentate and edentulous individuals $(69.55 \%$ and $79.46 \%$, respectively), with a significant difference detected between the two groups $(p=0.0086)$. Women accounted for $61.1 \%$ of the sample, $38.78 \%$ of the individuals were in the 65-to-69-year-old age group and $42.98 \%$ had less than four years of schooling. Nearly half were edentulous (49.19\%) and used a dental prosthesis and about $41.64 \%$ needed a dental prosthesis. Mean GOHAI scores for the physical, psychosocial and pain/discomfort subscales were 17.62 (95\%CI: 17.36-17.89), 22.35 (95\%CI: 22.03-22.68) and 13.79 (95\%CI: 13.6213.97), respectively.

Table 1 shows the association between poor self-perceived oral health and the independent variables. In relation to the total sample, poor self-perceived oral health was significant related seven independent variables. A significant association was observed between self-perceived oral health and six variables among dentate individuals and four variables in edentulous subjects. Mean GOHAI scores for the physical $(\mathrm{p}<0.001)$, psychosocial $(\mathrm{p}<0.001)$ and pain/discomfort subscales $(\mathrm{p}<0.001)$ were significantly higher among individuals with good self-perceived oral health when compared to those with poor oral health.

Association between poor self-perceived oral health and independent variables *.

\begin{tabular}{|c|c|c|c|c|c|c|}
\hline & \multicolumn{2}{|c|}{ Total } & \multicolumn{2}{|c|}{ Dentate } & \multicolumn{2}{|c|}{ Edentate } \\
\hline & $\%$ poor & p-value & $\%$ poor & p-value & $\%$ poor & p-value \\
\hline \multicolumn{7}{|l|}{ Sex } \\
\hline Male & 27.09 & 0.484 & 32.50 & 0.402 & 18.47 & 0.620 \\
\hline Female & 24.71 & & 28.68 & & 21.46 & \\
\hline \multicolumn{7}{|c|}{ Age (years) } \\
\hline $65-69$ & 26.06 & 0.713 & 28.79 & 0.840 & 22.19 & 0.174 \\
\hline $70-74$ & 23.79 & & 32.08 & & 14.45 & \\
\hline $75+$ & 26.98 & & 31.36 & & 23.99 & \\
\hline \multicolumn{7}{|c|}{ Level of education (years) } \\
\hline $0-3$ & 28.15 & & 31.74 & & 24.92 & \\
\hline $4-7$ & 26.18 & 0.142 & 34.19 & 0.184 & 18.26 & 0.176 \\
\hline $8+$ & 18.67 & & 22.25 & & 12.18 & \\
\hline \multicolumn{7}{|c|}{ Sufficient income } \\
\hline Yes & 21.81 & 0.032 & 26.31 & 0.086 & 16.69 & 0.104 \\
\hline No & 29.53 & & 35.08 & & 23.99 & \\
\hline \multicolumn{7}{|l|}{ Live alone } \\
\hline Yes & 33.65 & 0.060 & 41.53 & 0.054 & 23.76 & 0.490 \\
\hline No & 24.16 & & 28.30 & & 19.94 & \\
\hline \multicolumn{7}{|l|}{ Smoking } \\
\hline Yes & 27.28 & 0.763 & 52.78 & 0.035 & 15.47 & 0.369 \\
\hline No & 25.44 & & 28.85 & & 21.45 & \\
\hline
\end{tabular}

(continues) 


\begin{tabular}{|c|c|c|c|c|c|c|}
\hline & \multicolumn{2}{|c|}{ Total } & \multicolumn{2}{|c|}{ Dentate } & \multicolumn{2}{|c|}{ Edentate } \\
\hline & $\%$ poor & $\mathrm{p}$-value & $\%$ poor & $\mathrm{p}$-value & $\%$ poor & $\mathrm{p}$-value \\
\hline \multicolumn{7}{|c|}{ Number of diseases } \\
\hline $0-1$ & 20.24 & 0.002 & 24.51 & 0.021 & 14.29 & 0.014 \\
\hline $2+$ & 31.03 & & 38.20 & & 25.25 & \\
\hline \multicolumn{7}{|c|}{ Self-rated health } \\
\hline Good & 16.40 & 0.000 & 20.74 & 0.001 & 10.59 & 0.001 \\
\hline Poor & 34.55 & & 42.17 & & 28.11 & \\
\hline \multicolumn{7}{|l|}{ Depression } \\
\hline Yes & 45.33 & 0.000 & 64.33 & 0.000 & 18.03 & 0.026 \\
\hline No & 22.54 & & 26.47 & & 33.35 & \\
\hline \multicolumn{7}{|c|}{ Last dental visit (years) } \\
\hline$\leq 2$ & 26.20 & 0.730 & 27.88 & 0.133 & 21.30 & 0.832 \\
\hline $3+$ & 25.05 & & 37.82 & & 20.26 & \\
\hline \multicolumn{7}{|c|}{ Reason for last dental visit } \\
\hline Urgent care & 43.42 & & 59.95 & & 18.17 & \\
\hline Treatment & 27.68 & 0.000 & 31.79 & 0.000 & 22.91 & 0.258 \\
\hline Checkup & 6.45 & & 18.25 & & 14.84 & \\
\hline \multicolumn{7}{|c|}{ Use of dental prosthesis } \\
\hline No & 32.13 & 0.107 & 31.04 & 0.928 & 39.02 & 0.069 \\
\hline Yes & 24.67 & & 30.52 & & 19.81 & \\
\hline \multicolumn{7}{|c|}{ Need for dental prosthesis } \\
\hline No & 21.09 & 0.005 & 26.31 & 0.137 & 17.57 & 0.036 \\
\hline Yes & 32.13 & & 34.33 & & 27.86 & \\
\hline \multicolumn{7}{|c|}{ Number of teeth } \\
\hline 0 & 20.54 & & & & & \\
\hline $1-10$ & 32.31 & & 32.31 & & & \\
\hline $11-20$ & 35.80 & 0.003 & 35.80 & 0.049 & & \\
\hline $20+$ & 18.16 & & 18.16 & & & \\
\hline \multicolumn{7}{|c|}{ Periodontal disease } \\
\hline No & & & 28.19 & 0.029 & & \\
\hline Yes & & & 41.11 & & & \\
\hline \multicolumn{7}{|l|}{ Decayed teeth } \\
\hline No & & & 27.14 & 0.187 & & \\
\hline Yes & & & 35.41 & & & \\
\hline
\end{tabular}

* Rao-Scott test; total in the row.

Table 2 displays the results of the multiple logistic regression analysis for the overall sample. No socioeconomic variable was independently related to the outcome in the final model. The fully adjusted model demonstrates that individuals with poor self-rated general health were twice as likely to report poor oral health. Dental checkups and higher GOHAI scores for the physical and psychosocial subscales were inversely associated with poor self-rated oral health.

According to the multiple logistic regression model, poor self-perceived oral health among dentate elderly individuals was significantly associated with four variables (Table 3). Compared with individuals whose last dental visit was for urgent care, those individuals who sought a dentist for checkups and treatment were $68 \%$ and $78 \%$ less likely to report poor oral health, respectively. Regarding edentulous individuals, poor self-perceived oral health was independently associated with poor self-rated general health and the GOHAI psychosocial subscale (Table 4).

The probability of poor self-rated oral health for the total sample is displayed in Figure 1. Individuals who sought dental treatment were approximately $13 \%$ more likely to report poor self-rated oral health than those whose last dental visit was for a checkup. Moreover, a small 
Final logistic regression model for poor self-perceived oral health for overall sample (good =0; poor $=1$ ) *.

\begin{tabular}{|c|c|c|c|}
\hline & \multirow[t]{2}{*}{ Unadjusted } & \multicolumn{2}{|c|}{ Adjusted } \\
\hline & & Adding oral health & Adding GOHAI \\
\hline & OR (95\%IC) & OR (95\%IC) & OR (95\%IC) \\
\hline Sufficient income (yes) & $0.68(0.46-1.02)$ & $0.81(0.52-1.25)$ & $0.96(0.56-1.64)$ \\
\hline \multicolumn{4}{|l|}{ Age $(75+$ years $)$} \\
\hline $65-69$ & $0.95(0.57-1.57)$ & $0.91(0.50-1.66)$ & $0.86(0.46-1.59)$ \\
\hline $70-74$ & $0.83(0.56-1.24)$ & $0.84(0.54-1.31)$ & $0.69(0.42-1.13)$ \\
\hline Depression (yes) & $2.38(1.42-3.99) * *$ & $1.89(1.07-3.36)$ *** & $1.35(0.70-2.57)$ \\
\hline Self-rated health (poor) & $2.64(1.67-4.16) \#$ & $2.48(1.43-4.29) * \star$ & $2.15(1.23-3.74)$ ** \\
\hline \multicolumn{4}{|c|}{ Last dental visit (urgent care) } \\
\hline Treatment & $0.50(0.28-0.89) * \star \star$ & $0.51(0.29-0.91) * \star \star$ & $0.55(0.29-1.05)$ \\
\hline Checkup & $0.26(0.13-0.53) \#$ & $0.30(0.15-0.60) * *$ & $0.33(0.15-0.74)$ ** \\
\hline \multicolumn{4}{|l|}{ Number of teeth $(20+)$} \\
\hline 0 & $1.11(0.54-2.25)$ & $0.89(0.41-1.92)$ & $0.65(0.29-1.46)$ \\
\hline $1-10$ & 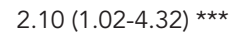 & $1.87(0.93-3.79)$ & $1.12(0.54-2.35)$ \\
\hline $11-20$ & 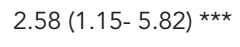 & 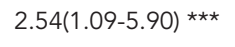 & $2.09(0.90-4.83)$ \\
\hline GOHAI physical \#\# & $0.80(0.75-0.86) \#$ & & $0.90(0.84-0.98) * * *$ \\
\hline GOHAl psychosocial \#\# & $0.76(0.71-0.81) \#$ & & $0.81(0.76-0.86) \#$ \\
\hline
\end{tabular}

GOHAl: General Oral Health Assessment Index.

$\star N=812$ representing 571,826 elderly individuals; model $p$-value $<0.001$;

** $\mathrm{p}<0.01$;

$\star \star \star x<0.05$

$\# \mathrm{p}<0.001$;

\#\# Continuous variables; higher score represents lower negative impact on quality of life.

Final logistic regression model for the poor self-perceived oral health in dentate elderly individuals $(\mathrm{good}=0$; poor $=1$ ) *

\begin{tabular}{|c|c|c|c|}
\hline & \multirow[t]{2}{*}{ Unadjusted } & \multicolumn{2}{|c|}{ Adjusted } \\
\hline & & Adding oral health & Adding GOHAl \\
\hline & OR $(95 \% \mathrm{Cl})$ & OR $(95 \% \mathrm{Cl})$ & OR (95\%Cl) \\
\hline Live alone (yes) & $1.83(1.00-3.32)$ ** & $1.67(0.84-3.33)$ & $1.69(0.81-3.51)$ \\
\hline Sufficient income (yes) & $0.63(0.39-1.00)$ & $0.70(0.42-1.17)$ & $0.95(0.51-1.76)$ \\
\hline \multicolumn{4}{|l|}{ Age $(75+$ years $)$} \\
\hline $65-69$ & $0.89(0.45-1.79)$ & $1.15(0.54-2.43)$ & $1.09(0.46-2.57)$ \\
\hline $70-74$ & $1.02(0.55-1.86)$ & $1.43(0.71-2.89)$ & $1.42(0.72-2.79)$ \\
\hline Depression (yes) & 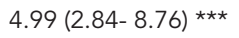 & $3.95(2.09-7.49) * \star \star$ & $2.58(1.25-5.33)$ ** \\
\hline Self-rated health (poor) & 2.75 (1.54- 4.89) \# & $2.23(1.21-4.12)$ ** & $1.97(1.07-3.65)$ ** \\
\hline \multicolumn{4}{|c|}{ Last dental visit (urgent care) } \\
\hline Treatment & $0.30(0.15-0.60) \#$ & $0.25(0.11-0.53) \#$ & $0.31(0.14-0.67) \#$ \\
\hline Checkup & $0.15(0.07-0.32)$ *** & $0.15(0.06-0.38) * \star \star$ & $0.21(0.08-0.58) \#$ \\
\hline GOHAI physical \#\# & $0.77(0.70-0.85) * \star \star$ & & $0.90(0.79-1.02)$ \\
\hline GOHAl psychosocial \#\# & $0.73(0.67-0.80) * \star \star$ & & 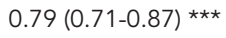 \\
\hline
\end{tabular}

GOHAl: General Oral Health Assessment Index.

* $N=385$ representing 304,191 elderly individuals; model p-value $<0.001$;

** $\mathrm{p}<0.05$

$\star \star * ~ p<0.001$

$\# p<0.01$

\#\# Continuous variables; higher score denotes lesser negative impact on quality of life. 
Final logistic regression model for poor self-perceived oral health in edentulous elderly individuals (good $=0$; poor $=1$ ) *

\begin{tabular}{|c|c|c|c|}
\hline & \multirow[t]{2}{*}{ Unadjusted } & \multicolumn{2}{|c|}{ Adjusted } \\
\hline & & Adding oral health & Adding GOHAI \\
\hline & OR $(95 \% \mathrm{Cl})$ & OR $(95 \% \mathrm{Cl})$ & OR (95\%Cl) \\
\hline Sufficient income (yes) & $0.65(0.37-1.14)$ & $0.80(0.44-1.48)$ & $0.88(0.41-1.90)$ \\
\hline \multicolumn{4}{|l|}{ Age $(75+$ years $)$} \\
\hline $65-69$ & $0.91(0.44-1.87)$ & $0.99(0.44-2.24)$ & $0.86(0.37-2.00)$ \\
\hline $70-74$ & $0.48(0.26-0.89)^{* *}$ & $0.48(0.26-0.89)$ & $0.33(0.17-0.66) * \star \star$ \\
\hline Self-rated health (poor) & $3.01(1.48-6.12) \#$ & $2.83(1.25-6.40) * \star$ & $2.37(1.10-5.10) * \star$ \\
\hline Depression (yes) & $1.81(0.85-3.88)$ & $1.31(0.59-2.88)$ & $0.86(0.35-2.13)$ \\
\hline Need for dental prosthesis (yes) & $1.91(1.08-3.39) * \star$ & $1.74(0.98-3.11)$ & $1.38(0.73-2.60)$ \\
\hline GOHAl physical \#\# & $0.81(0.74-0.88) * \star \star$ & & $0.92(0.84-1.00)$ \\
\hline GOHAI psychosocial \#\# & 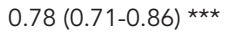 & & $0.82(0.74-0.91) \#$ \\
\hline
\end{tabular}

GOHAl: General Oral Health Assessment Index.

* $N=450$ representing 283,520 elderly individuals; model $p$-value $<0.001$;

** $\mathrm{p}<0.05$;

$\star \star \star ~ p<0.001 ;$

$\# p<0.01$;

\#\# Continuous variables; higher score denotes lesser negative impact on quality of life.

Figure 1

Probability of poor self-rated oral health according to inclusion of blocks of independent variables for overall sample.

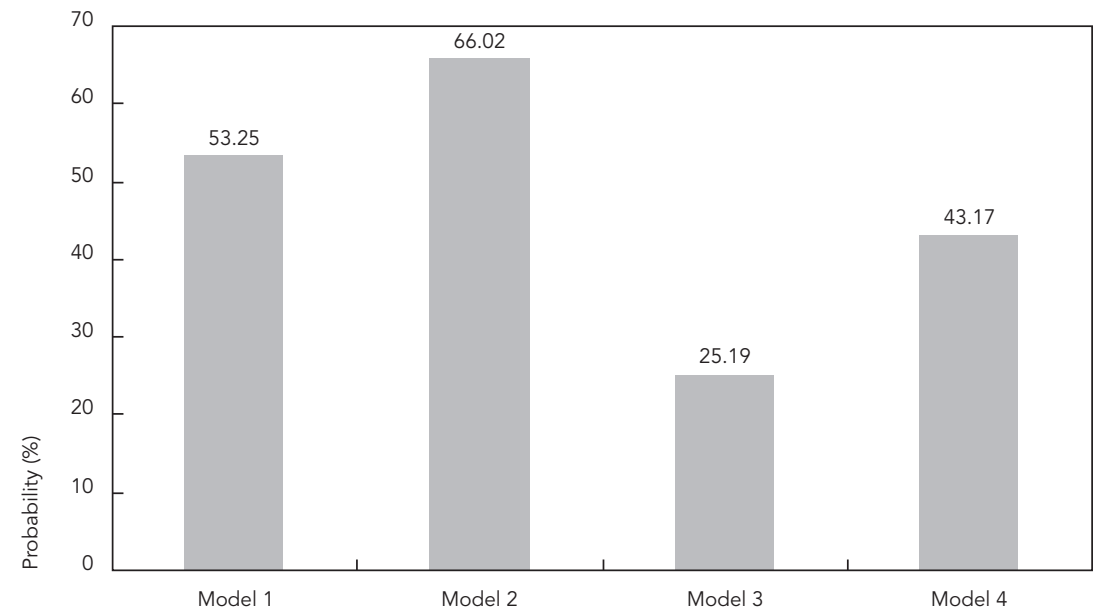

Model 1 - Socioeconomic status (SES) (64-79 years and self-reported of insufficient income) + general health (depression + poor self-reported general health) + oral health (dental checkups and 11-20 teeth)

Model 2 - Socioeconomic status (SES) (64-79 years and self-reported of insufficient income) + general health (depression + poor self-reported general health) + oral health (dental treatment and 11-20 teeth)

Model 3 - Model 1 + GOHAl [maximal values of functional and psychosocial scores used (20 and 25, respectively)]

Model 4 - Model 1 + GOHAl [mean values of functional and psychosocial scores used (17.24 and 22.47, respectively)] 
increase in mean to maximum GOHAI scores for the physical and psychosocial subscales represented an important decrease in the probability of poor oral health.

\section{Discussion}

The results of the present study reveal that about a quarter $(25.64 \%)$ of elderly individuals had poor self-perceived oral health and that this percentage was higher among dentate individuals (30.45\%) than in edentulous individuals $(20.54 \%)$ These findings are in agreement with the literature, which reports that most elderly individuals have good self-rated oral health 6,7,8,11,28,29,30. Moreover, poor self-rated general health and the psychosocial impact of oral health on quality of life, as measured by the GOHAI, were the best predictors of poor self-perceived oral health among all groups studied.

It has been suggested that oral health status is a result of a combination of the history of an individual's behavior, attitudes, culture and experiences and his/her own oral health 31,32 . Tooth loss and the use of dental prostheses among the elderly are characteristic of the aging process 14,31 and reflect cohort differences in the acceptance of dental diseases 31 which may explain the higher percentage of good self-perceived oral health among older adults.

Although differences in outcome measures and analysis need to be factored when making comparisons between studies, a review of the literature reveals discrepancies in results regarding associations between socioeconomic variables and self-perceived oral health. Some studies report a greater likelihood of positive self-rated oral health among individuals with a higher level of education $8,4,29$ and old age 29,33. Self-rated oral health has also been found to be related to gender 5 . In contrast, other studies report no relationship between self-rated oral health and schooling $5,6,28$, age $4,5,6,8$ or gender 6 . Moreover, studies have found a lower explanatory power for this block of variables in relation to self-perceived oral health, with $\mathrm{r}^{2}$ values ranging from 0.04 to $0.078,28,34,35$. The findings of the present study corroborate those reported by Martins et al. ${ }^{6}$, who found that none of these variables were independently related to self-perceived oral health after controlling for all variables. Self-perceived sufficient income for basic expenses was found to be related to the outcome in the first model among dentate individuals; however, the concomitant inclusion of the socioeconomic block of variables and general health factors in the multiple logistic regression model reduced the effect of sufficient income to no significant association, suggesting that the previous association was mediated by the variables subsequently added to the model.

Corroborating the findings of previous studies regarding general health factors 8,4,29,35,36, elderly individuals were more likely to have poor self-rated oral health in the fully adjusted model. When considering the dentate subjects, those with depression were 2.54 times more likely to report poor oral health than those without this condition. Few studies have used this variable in multiple regression analysis. Using a multi-item measure addressing self-perceived oral health, Sánchez-García et al. 18 found that depressed individuals seem to exaggerate negative perceptions of oral health status. The results of the present study are also similar to those reported by Mathias et al. ${ }^{8}$, who found that depression was a predictor of negative self-rated oral health regardless of the elderly individuals' actual health. Unlike edentulous elderly individuals with dental prostheses, who may be more likely to accept and adapt to their condition, the discomfort caused by the presence of poorly distributed teeth without replacement or the presence of periodontal disease, pain or dental caries may be exacerbated by symptoms of depression among dentate individuals. The same association has previously been described with regard to self-perceived general health 37,38 . Han \& Jylha 38 found that changes in depressive symptoms clearly coincide with changes in self-rated general health. An improvement in depressive symptoms decreased the chance of experiencing a decline in self-rated health and increased the chance of experiencing an improvement in self-rated health among community-dwelling disabled older adults. According to the literature, this effect could be due to overall negative evaluations of the self, world and future, which are key symptoms of depression and may be generalized to negative health perceptions 39

An interesting finding in relation to oral health factors was the lack of association between the outcome and clinical oral health measures. Although individuals with 11 to 20 teeth were more likely to report poor oral health in the overall sample, as observed by other authors $4,14,21$, this variable lost its significance after the introduction of variables related to the impact of oral health on quality of life, as measured by the GOHAI. This finding underscores the importance of subjective oral health measures. In contrast, previous studies report a significant association between self-rated oral health and clinical oral health indicators $6,21,28,35$. However, these variables were not the strongest predictors of self- 
rated oral health. Atchison \& Gift 4 found that edentulous individuals may report better selfperceived oral health than individuals with teeth because the adoption of full dentures among individuals who have experienced repeated dental problems may represent an improvement in oral health. Jokovic \& Locker 34 suggest that the weak association between clinical variables and dissatisfaction with oral health status may be due to the fact that most conditions detected by clinical examinations are asymptomatic and unknown to the individual.

A review of the literature reveals that selfperceived oral health is associated with the use of dental services 6,7. In the present study, however, self-perceived oral health was associated with the reason for the last dental visit and not the time elapsed since the last dental visit, which differs from findings of previous studies 5,6. Ekanayke \& Perera 28 report that the lack of association between the outcome and the time elapsed since the last dental visit may be explained by the fact that the last visit to the dentist may have been due to symptoms rather than for a regular checkup. Accordingly, the results of the present study revealed that dental checkups constituted a protective factor from poor self-reported oral health. Based on the probability curves, individuals who sought dental treatment had around 13\% greater probality poor self-rated oral health than those whose last dental visit was for a checkup. Afonso-Souza et al. 7 found that even intervals greater than two years between dental visits have little effect on the likelihood of poor selfperceived oral health. The authors report that dental checkups were independently associated with good self-perceived oral health and suggest that the explanation for this resides in the fact that dental checkups may reduce the incidence of missing teeth and improve the clinical condition of remaining teeth, as well as reassure and inform individuals, making them more confident regarding their oral health status.

Another important finding in the present study that merits attention is the strong independent association between self-rated oral health and the psychosocial subscale of the GOHAI. Although physical problems were related to self-rated oral health in the overall sample, this subscale lost its significance when the groups where evaluated separately. For both dentate and edentulous individuals, lower psychosocial impact denotes a lesser chance of reporting poor oral health, demonstrating that these elderly individuals were more disturbed by psychosocial problems than functional problems. Moreover, it was observed that even a small increase in the final scores for these subscales had a high impact on the probality of reporting poor self-rated oral health. Few previous studies have used subjective multi-item instruments to investigate associations with self-rated oral health, hindering direct comparisons with the findings of the present study. Some studies 5,6 report that dental appearance, which is one of the components of the psychosocial dimension, is the best predictor of self-perceived oral health regardless of socio-demographic and other clinical oral health factors. Similarly to the results of the present study, Locker et al. 29 found that both psychological discomfort and functional limitations, as measured by the Oral Health Impact Profile, were associated with perceptions of oral health. However, the functional dimension of the measure was considered the best predictor when all subjects were evaluated and no analysis was performed separately for dentate and edentulous elderly individuals.

A major strength of the present study is the use of a representative sample of communitydwelling elderly individuals, which increases the generalizability of the findings. However, the cross-sectional design of the study only allows for associations and lacks the capability to establish a cause-effect relationship underscoring the need for continued follow-up of these individuals. Moreover, although the second wave of the study is still representative of the population, there were some differences in relation to general health status between the remaining group and the individuals lost to follow-up (e.g., individuals who completed the follow-up were generally younger and had fewer diseases, as expected in a longitudinal study) and this may introduce bias when generalizing the study. Thus, according to the findings presented, it can be concluded that poor self-rated oral health is associated with general health factors and the psychosocial impact of oral health on quality of life, regardless of socioeconomic and clinical health measures. 


\section{Resumo}

Este estudo avaliou a prevalência de autopercepção de saúde bucal como ruim em idosos de São Paulo, Brasil, e investigou sua relação com a saúde bucal, saúde geral e fatores socioeconômicos. A amostra foi composta por 871 idosos do estudo de coorte Saúde, Bem-Estar e Envelhecimento. A autopercepção da saúde bucal foi medida pela pergunta: "Como você classifica a sua saúde bucal?". A maioria dos idosos apresentou autoavaliação de saúde bucal boa. A autopercepção de saúde bucal como ruim, entre indivíduos dentados, foi relacionada à depressão, autoavaliação de saúde ruim, check-up odontológico, tratamento dentário e dimensão psicossocial do Geriatric Oral Health Assessment Index. Desdentados com autoavaliação de saúde ruim apresentaram maior probabilidade de relatar saúde bucal ruim, enquanto aqueles com maior pontuação na dimensão psicossocial tiveram menor chance de autoavaliação ruim. A autoavaliação de saúde bucal ruim foi associada com fatores de saúde geral e com o impacto psicossocial da saúde bucal na qualidade de vida, independentemente de medidas socioeconômicas e clínicas de saúde bucal.

Saúde Bucal; Qualidade de Vida; Idoso

\section{Contributors}

F. B. Andrade worked on the conception and design of the research project, analysis and interpretation of data, drafting and critically reviewing the article and approving the final version for publication. M. L. Lebrão worked on the conception and design of the research project, analysis and interpretation of data, drafting and critically reviewing the article and approved the final version for publication. J. L. F. Santos, Y. A. O. Duarte and D. S. C. Teixeira worked on the analysis and interpretation of data, critical review of the article and approved the final version for publication.

\section{Acknowledgments}

This study was sponsored by FAPESP (grant numbers 1999/05125-7, 2005/54947-2 and 2010/00883-1). J. L. F. Santos and Y. A. O. Duarte received research productivity fellowships from CNPq.

\section{References}

1. Dye BA, Tan S, Smith V, Lewis BG, Barker LK, Thornton-Evans G, et al. Trends in oral health status: United States, 1988-1994 and 1999-2004. Vital Health Stat 11 2007; (248):1-92.

2. Petersen PE. The World Oral Health Report 2003: continuous improvement of oral health in the 21st century - the approach of the WHO Global Oral Health Programme. Community Dent Oral Epidemiol 2003; 31 Suppl 1:3-23.

3. Ministério da Saúde. Projeto SBBrasil 2010: Pesquisa Nacional de Saúde Bucal - resultados principais. Brasília: Ministério da Saúde; 2011.

4. Atchison KA, Gift HC. Perceived oral health in a diverse sample. Adv Dent Res 1997; 11:272-80.
5. Patussi MP, Peres KG, Boing AF, Peres MA, Costa JS. Self-rated oral health and associated factors in Brazilian elders. Community Dent Oral Epidemiol 2010; 38:348-59.

6. Martins AM, Barreto SM, Silveira MF, Santa-Rosa TT, Pereira RD. Self-perceived oral health among Brazilian elderly individuals. Rev Saúde Pública 2010; 44:912-22.

7. Afonso-Souza G, Nadanovsky P, Chor D, Faerstein E, Werneck GL, Lopes CS. Association between routine visits for dental checkup and self-perceived oral health in an adult population in Rio de Janeiro: the Pró-Saúde Study. Community Dent Oral Epidemiol 2007; 35:393-400. 
8. Mathias RE, Atchison KA, Lubben JE, De Jong F, Schweitzer SO. Factors affecting self-ratings of oral health. J Public Health Dent 1995; 55:197-204.

9. Kaplan G, Baron-Epel O. What lies behind the subjective evaluation of health status? Soc Sci Med 2003; 56:1669-76.

10. Reisine ST. The impact of dental conditions on social and quality of life. Ann Rev Public Health 1988; 9:1-19.

11. Jones JA, Kressin NR, Spiro 3rd A, Randall CW, Miller DR, Hayes C, et al. Self-reported and clinical oral health in users of VA health care. J Gerontol A Biol Sci Med Sci 2001; 56:M55-62.

12. Steele JG, Sanders AE, Slade GD, Allen PF, Lahti S, Nuttall N, et al. How do age and tooth loss affect oral health impacts and quality of life? A study comparing two national samples. Community Dent Oral Epidemiol 2004; 32:107-14.

13. Atchison KA, Dolan TA. Development of the Geriatric Oral Health Assessment Index. J Dental Educ 1990; 54:680-7.

14. Martins AMEBL, Barreto, SM, Pordeus IA. Autoavaliação de saúde bucal em idosos: análise com base em modelo multidimensional. Cad Saúde Pública 2009, 25:421-35.

15. Kressin NR, Atchison KA, Miller DR. Comparing the impact of oral disease in two populations of older adults: application of the geriatric oral health assessment index. J Public Health Dent 1996; 57:224-32.

16. Robinson PG, Gibson B, Khan FA, Birnbaum W. Validity of two oral health-related quality of life measures. Community Dent. Oral Epidemiol 2003; 31:90-9.

17. John MT, LeResche L, Koepsell TD, Hujoel $\mathrm{P}$, Miglioretti DL, Micheelis W. Oral health-related quality of life in Germany. Eur J Oral Sci 2003; 111:483-91.

18. Sánchez-García S, Heredia-Ponce E, Juárez-Cedillo T. Psychometric properties of the General Oral Health Assessment Index (GOHAI) and dental status of an elderly Mexican population. J Public Health Dent 2010; 70:300-7.

19. Lebrao ML, Duarte YAO. SABE - Saude, Bem-estar e Envelhecimento - O projeto SABE no município de São Paulo? Uma abordagem inicial. Brasília: Organização Pan-Americana da Saúde; 2003.

20. Tamanini JT, Santos JL, Lebrão ML, Duarte YAO, Laurenti R. Association between urinary incontinence in elderly patients and caregiver burden in the city of Sao Paulo/Brazil: Health, Wellbeing, and Ageing Study. Neurourol Urodyn 2011; 30:1281-5.

21. Matos DL, Lima-Costa MF. Auto-avaliação da saúde bucal entre adultos e idosos residentes na Região Sudeste: resultados do Projeto SB-Brasil, 2003. Cad Saúde Pública 2006; 22:1699-707.

22. Yesavage JA, Brink TL, Rose TL, Lum O, Huang V, Adey M, et al. Development and validation of a geriatric depression screening scale: a preliminary report. J Psychiatr Res 1983; 17:37-49.

23. Almeida OP, Almeida SA. Short versions of the geriatric depression scale: a study of their validity for the diagnosis of a major depressive episode according to ICD-10 and DSM-IV. Int J Geriatr Psychiatry 1999; 14:858-65.
24. Rao JNK, Scott AJ. On chi-squared tests for multiway contingency tables with cell proportions estimated from survey data. Ann Stat 1984; 12:46-60.

25. Icasa MC, Albala C. Proyecto SABE - Minimental State Examination (MMSE): del estúdio de dementia en Chile: análisis estadístico. Washington DC: Organización Panamericana de Salud; 1999.

26. Kleinbaum DG, Kupper LL, Muller KE. Applied regression analysis and other multivariate methods. 2nd Ed. Belmont: Duxbury Press; 1988.

27. Leahy K. Multicollinearity: when the solution is the problem. In: Rud OP, editor. Data mining cookbook. New York: John Wiley \& Sons; 2001. p. 106-8.

28. Ekanayke L, Perera I. Factors associated with perceived oral health status in older individuals. Int Dent J 2005; 55:31-7.

29. Locker D, Mscn EW, Jokovic A. What do older adults' global self-ratings of oral health measure? J Public Health Dent 2005; 65:146-52.

30. Benyamini Y, Leventhal H, Leventhal EA. Self-rated oral health as an independent predictor of self-rated general health, self-esteem and life satisfaction. Soc Sci Med 2004; 59:1109-16.

31. Kiyak HA. Age and culture: influences on oral health behaviour. Int Dent J 1993; 43:9-16.

32. Ettinger RL. Cohort differences among aging populations: a challenge for the dental profession. Spec Care Dentist 1993; 13:19-26.

33. Ståhlnacke K, Unell L, Söderfeldt B, Ekbäck G, Ordell S. lf-perceived oral health among 65 and 75 year olds in two Swedish counties. Swed Dent J 2010; 34:107-19.

34. Jokovic A, Locker D. Dissatisfaction with oral health status in an older adult population. J Public Health Dent 1997; 57:40-7.

35. Gift HC, Atchison KA, Drury TF. Perceptions of the natural dentition in the context of multiple variables. J Dent Res 1998; 77:1529-38.

36. Ugarte J, Abe Y, Fukuda H, Honda S, Takamura N Kobuke Y, et al. Self-perceived oral health status and influencing factors of the elderly residents of a peri-urban area of La Paz, Bolivia. Int Dent J 2007; 57:19-26.

37. Schüz B, Wurm S, Schöllgen I, Tesch-Römer C. What do people include when they self-rate their health? Differential associations according to health status in community-dwelling older adults. Qual Life Res 2011; 20:1573-80.

38. Han B, Jylha M. Improvement in depressive symptoms and changes in self-rated health among community-dwelling disabled older adults. Aging Ment Health 2006; 10:599-605.

39. Beck AT. Cognitive models of depression. J Cogn Psychother 1987; 1:1-37.

Submitted om 01/Oct/2011

Final version resubmitted on 27/Apr/2012

Approved on 02/Jul/2012 